\title{
A MODEL OF THE EFFICIENCY OF GOALKEEPERS' ACTIONS IN FUTSAL
}

original paper

( ) University School of Physical Education in Wroclaw

DOI: https://doi.org/10.5114/hm.2020.95990

\author{
ANDRZEJ SZWARC ${ }^{1}$, MATEUSZ OSZMANIEC ${ }^{2}$ \\ ${ }^{1}$ Soccer Laboratory, Faculty of Physical Education, Gdańsk University of Physical Education and Sport, Gdańsk, Poland \\ ${ }^{2}$ Town Hall of Bytów, Bytów, Poland
}

\begin{abstract}
Purpose. The aim of the study was to develop a model of the efficiency of actions of goalkeepers from top-level futsal teams. Methods. Goalkeepers' activity, successful activity, and effectiveness were estimated with the consideration of accomplishing the game objectives in offence and defence and of the changing match status. The study applied the method of observation. Data about the game were registered on a self-developed observation sheet. Overall, 62 games of 23 goalkeepers participating in 31 matches of the World and European Championships and the UEFA Futsal Cup played in years 2012-2015 were observed. Results. It was found that actions to gain the playfield with the ball ( $41 \%$ of all actions) and to prevent a loss of a goal (28.2\%) dominated in futsal goalkeepers' game. Offensive actions accounted for $58 \%$ and defensive actions for $42 \%$ of all actions undertaken by the studied futsal goalkeepers in the observed matches. The examined competitors achieved the highest effectiveness in keeping the ball (97\%) and in preventing scoring situations (96\%).
\end{abstract}

Conclusions. The created model mapping the top-skilled goalkeepers' actions allows improving the process of coaching players by referring their game to objective patterns.

Key words: futsal, goalkeeper, notational analysis, activity and effectiveness of actions

\section{Introduction}

Contemporary soccer is evolving very dynamically, which means that the demands placed on players are increasingly higher. A very balanced level of top players' skills implies that the final success is determined by nuances associated with their motor, technicaltactical, and mental preparation [1, 2]. Therefore, the main task of the coaching staff is to rationalize training in this area [3, 4]. Defining elements of training accents in technical and tactical terms must directly result from the knowledge of the players' game obtained from observations made with objective research tools $[5,6]$. Reliable assessment of players' performance is possible by tracking their behaviours in real-game conditions, with an opponent of a similar level of sports proficiency and with the consideration of situational aspects of competition [7-9].

For several years, intensive research has been conducted on players' efficiency in the game of futsal, which is significantly different from traditional soccer. The differences result from separate rules of the game and are conditioned by the competitive environment. It follows from a review of already rich literature on the efficiency in the game of futsal [10-18] that conceptual eclecticism and a variety of methodological approaches dominate in exploring this game, which prevents reliable comparative analyses. Research usually focuses on selected aspects of offensive actions, whose aim is to score goals and to position the game (type of attack, how to score goals, set-pieces and their effectiveness), and on defensive actions (type of defence, method and place of receiving the ball). Goalkeepers' efficiency is rarely tested. Most research concerns the goalkeeper's participation in offensive actions in situations of outnumbering when each team uses the $5 \mathrm{vs} 4$ + GK format [19-23], efficiency in preventing a loss of a goal [24-26], and the topography and ways of defending shots [27, 28]. Few studies have comprehensively analysed efficient action in the game [29, 30].

Correspondence address: Andrzej Szwarc, Akademia Wychowania Fizycznego i Sportu, ul. Kazimierza Górskiego 1, 80-336 Gdańsk, Poland, e-mail: andrzej.szwarc@awf.gda.pl

Received: March 2, 2020

Accepted for publication: May 18, 2020

Citation: Szwarc A, Oszmaniec M. A model of the efficiency of goalkeepers' actions in futsal. Hum Mov. 2020;21(4):44-53; doi: https://doi.org/10.5114/hm.2020.95990. 
Praxeological interpretation of the assessment of the efficiency of actions allows to comprehensively analyse players' activity by means of objective research tools. Accordingly, research on the efficiency of actions of players of the highest sports proficiency level aims at creating so-called models of game design. In praxeological terms, efficiency of actions is understood as a total of practical qualities of play, which includes activity (number of actions performed by players of one team during a match), successful activity (number of positive actions with reference to the game aims), and effectiveness (the ratio between the number of effective actions and the number of all actions of one type during the game). Other indices of play efficiency encompass rationality (actions cognitively justified), valuableness (value of assessment of action efficiency), and economy (loss-gain ratio) [31]. By analysing the observed sequences with regard to changing situations in the game, by estimating and systematizing them, models that map players' actions are created. Thanks to this, it is possible to rationalize game activities by referring them to objective patterns.

Therefore, the purpose of this research was to develop a model of the efficiency of actions of goalkeepers from top-level futsal teams taking into account their offensive and defensive objectives.

The following research questions were formulated:

1. What activities do futsal goalkeepers most often perform in phases of attack and defence?

2. What is the activity, successful activity, and effectiveness of individual and team actions in offensive and defensive game of futsal goalkeepers of the highest level of sports proficiency?

\section{Material and methods}

Overall, 23 goalkeepers (age: $27.03 \pm 3.86$ years, body height: $182 \pm 5.64 \mathrm{~cm}$ ) were examined in 31 matches, rendering 62 game analyses in total (Table 1). The examined group comprised players of the highest level of sports proficiency competing in the World and European Championships and the UEFA Futsal Cup held in 2012-2015.

Goalkeepers' game was analysed within the regular, 40-minute game time. The analysis excluded the goalkeepers' play time in which they were substituted by players from the field in the case of an unfavourable competition result.

This study used the method of notational observation [32]. The analysis was conducted with the use of video footage recorded on a DVD, and the tested action was observed during a multiple replay of a game situation. Data about the game were recorded on a special originally developed observation sheet meeting scientific requirements [33]; the intra-class correlation coefficient test was used, with the intra-rater reliability of 1.00 (95\% CI: 1.00-1.00) and the inter-rater reliability of 0.99 (95\% CI: 0.99-1.00) [cf. 34].

Activity, successful activity, and effectiveness of goalkeepers' actions in terms of the game objectives were investigated. In attacking, the efficiency of actions that aimed at keeping the ball, gaining the playfield with the ball, creating situations to score, and scoring a goal was estimated, while in defence, the efficiency of actions against losing a goal and against creating a situation to score was evaluated.

\section{Ethical approval}

The conducted research is not related to either human or animal use.

\section{Results}

General model of futsal goalkeeper's efficiency of actions

The data presented in Table 2 show that in the game of goalkeepers of the best futsal teams participating in the World and European Championships and the UEFA Futsal Cup in 2012-2015, actions to gain the playfield ( $41 \%$ of all actions) and to prevent a loss of a goal (28.2\%) dominated. Goalkeepers less often prevented creating situations to score a goal (13.8\% of all actions) and kept the ball (12.6\%). They performed least frequently actions that created situations to score and scored ( $2.9 \%$ and $1.5 \%$ of all actions, respectively).

The examined goalkeepers were the most efficient in keeping the ball (9 actions in one match on average, with $97 \%$ effectiveness) and in preventing the creation of scoring situations (10 actions on average, with 96\% effectiveness). In gaining the playfield with the ball, they had 88\% effectiveness, performing the most actions, on average, 58 times in a match. Equally often, futsal goalkeepers prevented a loss of a goal (20 actions in one match on average, with $87 \%$ effectiveness). Less often did they perform actions aimed at creating a goal-scoring situation and at scoring a goal (an average of 2 and 1 action in a match, with $64 \%$ and $7 \%$ effectiveness).

From the detailed data presenting the number of all actions performed by futsal goalkeepers in terms of the achieved game objectives (Table 2 and Figure 1), it follows that cooperation with partners significantly outnumbered individual actions in situations of keep- 


\section{HUMAN MOVEMENT}

A. Szwarc, M. Oszmaniec, A model of the efficiency of goalkeepers' actions in futsal

Table 1. List of matches in which the goalkeepers' game was analysed along with their real play time

\begin{tabular}{|c|c|c|c|c|c|c|}
\hline No. & $\begin{array}{c}\text { Level of } \\
\text { competition }\end{array}$ & Match & $\begin{array}{c}\text { Phase } \\
\text { of competition }\end{array}$ & $\begin{array}{c}\text { Score } \\
\text { (score after extra time) }\end{array}$ & $\begin{array}{l}\text { Examined } \\
\text { goalkeepers }\end{array}$ & $\begin{array}{l}\text { Real play } \\
\text { time (min) }\end{array}$ \\
\hline 1. & WC 2012 & Argentina-Brazil & Quarterfinal & $2-2(2-3)$ & Elias/Tiago & $40 / 40$ \\
\hline 2. & WC 2012 & Colombia-Ukraine & Quarterfinal & $3-1$ & Lozano/Ivanyak & 40/38’08 \\
\hline 3. & WC 2012 & Spain-Russia & Quarterfinal & $3-2$ & Juanjo/Gustavo & 40/33’51 \\
\hline 4. & WC 2012 & Italy-Spain & Semifinal & $1-4$ & Mammarella/Juanjo & $33 ’ 20 / 40$ \\
\hline 5. & WC 2012 & Brazil-Colombia & Semifinal & $3-1$ & Tiago/Lozano & $40 / 40$ \\
\hline 6. & WC 2012 & Italy-Colombia & $3^{\text {rd }}$ place play-offs & $3-0$ & Mammarella/Nanez & $40 / 40$ \\
\hline 7. & WC 2012 & Spain-Brazil & Final & $2-2(2-3)$ & Juanjo/Tiago & $40 / 40$ \\
\hline 8. & EC 2012 & Croatia-Ukraine & Quarterfinal & $\begin{array}{c}1-1 \\
\text { (after penalty shoot-out: } 3-1 \text { ) }\end{array}$ & Jukić/Ivanyak & $40 / 40$ \\
\hline 9. & EC 2012 & Romania-Spain & Quarterfinal & $3-8$ & Lancu/Amado & $20 / 40$ \\
\hline 10. & EC 2012 & Russia-Serbia & Quarterfinal & $2-1$ & Zuev/Aksentijević & 40/37’02 \\
\hline 11. & EC 2012 & Italy-Portugal & Quarterfinal & $3-1$ & Mammarella/Benedito & $40 / 36^{\prime} 35$ \\
\hline 12. & EC 2012 & Croatia-Russia & Semifinal & $2-4$ & Jukić/Gustavo & $34^{\prime} 49 / 40$ \\
\hline 13. & EC 2012 & Spain-Italy & Semifinal & $1-0$ & Amado/Mammarella & $40 / 36^{\prime} 22$ \\
\hline 14. & EC 2012 & Croatia-Italy & $3^{\text {rd }}$ place play-offs & $1-3$ & Jukić/Mammarella & $29^{\prime} 33 / 40$ \\
\hline 15. & EC 2012 & Russia-Spain & Final & $1-1(1-3)$ & Gustavo/Amado & $40 / 35^{\prime} 12$ \\
\hline 16. & EC 2014 & Ukraine-Portugal & Quarterfinal & $1-2$ & Lytvynenko/Benedito & $37 ’ 10 / 40$ \\
\hline 17. & EC 2014 & Romania-Russia & Quarterfinal & $0-6$ & Lancu/Gustavo & $21 / 40$ \\
\hline 18. & EC 2014 & Italy-Croatia & Quarterfinal & $2-1$ & Mammarella/Jukić & 40/33’08 \\
\hline 19. & EC 2014 & Slovenia-Spain & Quarterfinal & $0-4$ & Mordej/Rafa & $35 ’ 15 / 40$ \\
\hline 20. & EC 2014 & Portugal-Italy & Semifinal & $3-4$ & Benedito/Mammarella & $34^{\prime} 28 / 40$ \\
\hline 21. & EC 2014 & Russia-Spain & Semifinal & $3-3(4-3)$ & Gustavo/Rafa & 40/38'18 \\
\hline 22. & EC 2014 & Italy-Russia & Final & $3-1$ & Mammarella/Gustavo & $40 / 36$ \\
\hline 23. & $\begin{array}{c}\text { UEFA } \\
2011 / 2012\end{array}$ & $\begin{array}{c}\text { Marca Futsal-MFK } \\
\text { Dinamo Moscow }\end{array}$ & Semifinal & $0-3$ & Higuita/Popov & $36^{\prime} 01 / 40$ \\
\hline 24. & $\begin{array}{c}\text { UEFA } \\
2011 / 2012\end{array}$ & $\begin{array}{c}\text { MFK Dinamo Moscow- } \\
\text { FC Barcelona }\end{array}$ & Final & $1-3$ & Popov/Sedano & $34^{\prime} 09 / 40$ \\
\hline 25. & $\begin{array}{c}\text { UEFA } \\
2012 / 2013\end{array}$ & $\begin{array}{l}\text { Iberia Star-MFK } \\
\text { Dinamo Moscow }\end{array}$ & Semifinal & $2-5$ & Celio/Popov & $25 ’ 51 / 40$ \\
\hline 26. & $\begin{array}{c}\text { UEFA } \\
2012 / 2013\end{array}$ & $\begin{array}{l}\text { FC Barcelona- } \\
\text { Kairat Almaty }\end{array}$ & Semifinal & $4-5$ & Sedano/Higuita & $35^{\prime} 23 / 40$ \\
\hline 27. & $\begin{array}{c}\text { UEFA } \\
2012 / 2013\end{array}$ & $\begin{array}{c}\text { MFK Dinamo Moscow- } \\
\text { Kairat Almaty }\end{array}$ & Final & $3-4$ & Popov/Higuita & $28^{\prime} 33 / 40$ \\
\hline 28. & $\begin{array}{c}\text { UEFA } \\
2014 / 2015\end{array}$ & $\begin{array}{l}\text { MFK Dina Moscow- } \\
\text { Kairat Almaty }\end{array}$ & Semifinal & $3-3(4-7)$ & Zuev/Higuita & $355^{\prime} 45 / 40$ \\
\hline 29. & $\begin{array}{c}\text { UEFA } \\
2014 / 2015\end{array}$ & $\begin{array}{l}\text { FC Barcelona- } \\
\text { Sporting CP }\end{array}$ & Semifinal & $5-3$ & Sedano/Benedito & $40 / 35^{\prime} 30$ \\
\hline 30. & $\begin{array}{c}\text { UEFA } \\
2014 / 2015\end{array}$ & $\begin{array}{l}\text { MFK Dina Moscow- } \\
\text { Sporting CP }\end{array}$ & $3^{\text {rd }}$ place play-offs & $3-8$ & Trushkin/Cristiano & $35 ’ 55 / 40$ \\
\hline 31. & $\begin{array}{c}\text { UEFA } \\
2014 / 2015\end{array}$ & $\begin{array}{l}\text { Kairat Almaty- } \\
\text { FC Barcelona }\end{array}$ & Final & $3-2$ & Higuita/Sedano & $40 / 35^{\prime} 40$ \\
\hline
\end{tabular}

WC - Futsal World Cup, EC - European Futsal Championship, UEFA - UEFA Futsal Cup 
Table 2. General model of futsal goalkeepers' efficiency of actions

\begin{tabular}{lcccc}
\hline & \multicolumn{4}{c}{ Indicator } \\
\cline { 2 - 5 } Type of action & $\begin{array}{c}\text { Number } \\
\text { of actions }\end{array}$ & $\begin{array}{c}\text { Number } \\
\text { of successful } \\
\text { actions }\end{array}$ & $\begin{array}{c}\text { Effectiveness } \\
\text { of actions (\%) }\end{array}$ & $\begin{array}{c}\text { Percentage } \\
\text { of all actions (\%) }\end{array}$ \\
\hline Keeping the ball & 555 & 538 & 97 & 12.6 \\
Gaining the playfield with the ball & 1799 & 1581 & 88 & 41 \\
Creating situations to score a goal & 127 & 81 & 64 & 2.9 \\
Scoring a goal & 68 & 5 & 7 & 1.5 \\
Preventing a loss of a goal & 1237 & 1076 & 87 & 28.2 \\
Preventing the creation of scoring situations & 606 & 580 & 96 & 13.8 \\
\hline
\end{tabular}

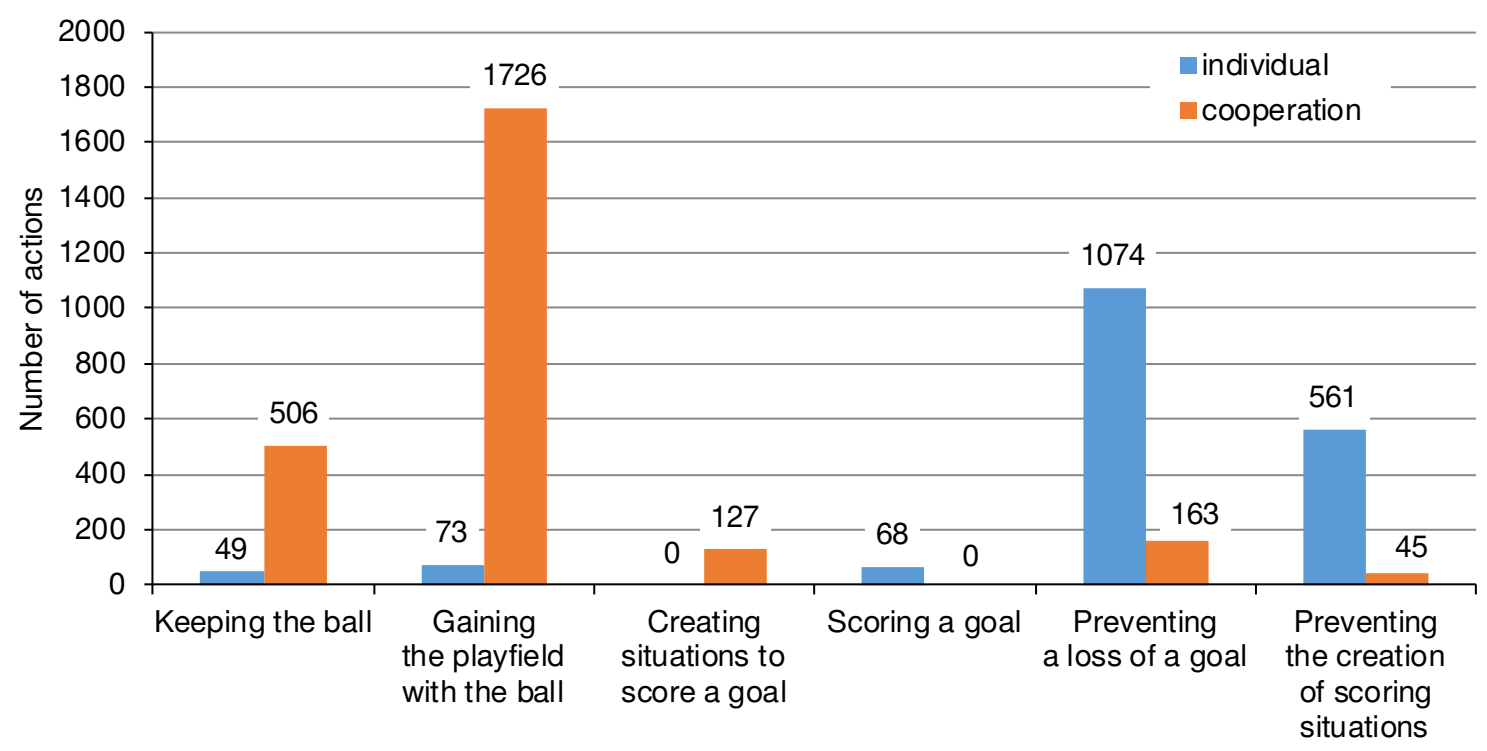

Types of actions

Figure 1. The number of all actions used by the examined goalkeepers in terms of their objectives and ways of acting

ing the ball, gaining the playfield with the ball, and creating situations to score. The differences in favour of cooperation were 457, 1653, and 127 actions, respectively. During actions aimed at scoring a goal, as well as preventing a loss of a goal and creating a goalscoring situation, individual actions dominated (the differences were: $68,911,516$ actions, respectively). While scoring goals, only individual actions were performed, and while creating situations to score a goal, all actions strictly depended on cooperation.

Detailed models of the efficiency

of offensive actions

\section{Keeping the ball}

From the data presented in Table 3, it appears that during actions aimed at keeping the ball, the examined goalkeepers most often received the ball passed by a partner (481 actions with $97 \%$ effectiveness) and faked and/or dribbled the ball (42 actions, with 95\% effectiveness). The subjects did not fail while catching the ball after faking or dribbling and while keeping the ball in play by sliding tackle and passing the ball from a set-piece (respectively: 6, 1, and 1 action). The lowest effectiveness was demonstrated while catching the ball after partner's playing (11 actions, with $91 \%$ effectiveness).

\section{Gaining the playfield with the ball}

The data presented in Table 4 and in Figure 1 show that the examined goalkeepers cooperated 1726 times in gaining the playfield with the ball, with $88 \%$ effectiveness. They used individual actions 73 times during faking and/or dribbling the ball, with 95\% effectiveness. In cooperation, they threw the ball more often than kicked it with their feet (1015 and 711 actions, 


\section{HUMAN MOVEMENT}

A. Szwarc, M. Oszmaniec, A model of the efficiency of goalkeepers' actions in futsal

Table 3. Model of efficiency in keeping the ball

\begin{tabular}{llrr}
\hline \multirow{2}{*}{ Mode of action } & & \multicolumn{2}{c}{ Forms of efficiency } \\
\cline { 3 - 4 } Individual & Sliding tackle to keep the ball in play & Activity & Successful activity \\
& Faking and/or dribbling the ball & 1 & 1 \\
& Catching the ball after faking or dribbling & 42 & 40 \\
Cooperation & Catching the ball after partner's playing & 6 & 11 \\
& Receiving the ball from a partner & 481 & 468 \\
& Passing the ball (playing backwards) & 13 & 12 \\
& Passing the ball from a set-piece & 1 & 1 \\
\hline
\end{tabular}

Table 4. Model of efficiency in gaining the playfield with the ball

\begin{tabular}{|c|c|c|c|c|c|}
\hline \multirow{2}{*}{ Mode of action } & & & & \multicolumn{2}{|c|}{ Forms of efficiency } \\
\hline & & & & \multirow{2}{*}{$\frac{\text { Activity }}{73}$} & \multirow{2}{*}{$\frac{\text { Successful activity }}{69}$} \\
\hline Individual & Faking and/or dribbling the ball & & & & \\
\hline \multirow{9}{*}{ Cooperation } & \multirow{3}{*}{ Throwing the ball by hand } & \multirow{3}{*}{\multicolumn{2}{|c|}{$\begin{array}{l}\text { with underhand swing } \\
\text { single-handed overhead swing } \\
\text { in 'another way' }\end{array}$}} & 748 & 731 \\
\hline & & & & 142 & 102 \\
\hline & & & & 125 & 110 \\
\hline & \multirow{6}{*}{$\begin{array}{l}\text { Passing the ball with a foot } \\
\text { from the ground }\end{array}$} & \multirow{2}{*}{ after receiving } & $\mathrm{s}$ & 344 & 329 \\
\hline & & & 1 & 179 & 85 \\
\hline & & \multirow{2}{*}{ without receiving } & $\mathrm{s}$ & 42 & 37 \\
\hline & & & 1 & 34 & 22 \\
\hline & & \multirow{2}{*}{ in 'another way' } & s & 108 & 96 \\
\hline & & & 1 & 4 & 0 \\
\hline
\end{tabular}

$\mathrm{s}$ - short pass of the ball, 1 - long pass of the ball

Table 5. Model of efficiency in creating scoring situations

Mode of action

Forms of efficiency

\begin{tabular}{|c|c|c|c|c|}
\hline 10 & & & Activity & Successful activity \\
\hline \multirow{4}{*}{ Cooperation } & \multirow{2}{*}{ Throwing the ball with a hand } & overhead single-handed & 60 & 39 \\
\hline & & in 'another way' & 9 & 7 \\
\hline & \multirow{2}{*}{ Passing the ball with a foot from the ground } & after receiving & 46 & 29 \\
\hline & & in 'another way' & 12 & 6 \\
\hline
\end{tabular}

Table 6. Model of efficiency in scoring a goal

Mode of action

Forms of efficiency

\begin{tabular}{|c|c|c|c|c|}
\hline \multicolumn{2}{|l|}{ 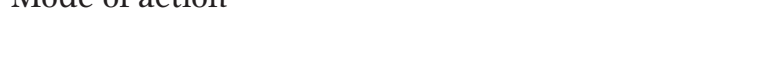 } & & \multicolumn{2}{|c|}{ Activity Successful activity } \\
\hline \multirow[b]{2}{*}{ Individual } & Hitting the ball from the ground & & 52 & 1 \\
\hline & Hitting the ball dropped from a hand & $\begin{array}{l}\text { on the half-volley } \\
\text { in 'another way' }\end{array}$ & $\begin{array}{l}7 \\
9\end{array}$ & $\begin{array}{l}4 \\
0\end{array}$ \\
\hline
\end{tabular}


respectively, with $93 \%$ and $80 \%$ effectiveness). The examined players most often and most effectively gained the playfield by throwing the ball with underhand swing (748 actions, with $98 \%$ effectiveness) and by short passes with the foot from the ground after receiving the ball (344 actions, with $96 \%$ effectiveness). The most seldom did they use long passes from the ground in 'another way' (4 actions), all of which were ineffective. The investigated goalkeepers equally often failed in a long pass with a foot after receiving or without receiving the ball (179 and 34 actions, respectively, with $47 \%$ and $65 \%$ effectiveness).

\section{Creating scoring situations}

It follows from the data presented in Table 5 and Figure 1 that the observed goalkeepers cooperated only in creating scoring situations. They used ball throws more often than passes with a foot (69 and 58 actions, with $67 \%$ and $60 \%$ effectiveness, respectively). Most often, they used a single-handed overhead throw of the ball (60 actions, with 65\% effectiveness) and passed the ball with a foot from the ground after receiving it (46 actions, with 63\% effectiveness). The goalkeepers most often failed in passing the ball with a foot from the ground in 'another way' (12 actions, with 50\% effectiveness).

\section{Scoring a goal}

The data presented in Table 6 and Figure 1 show that the surveyed goalkeepers of sports-effective teams performed 68 individual actions aimed at scoring a goal (7\% effectiveness). Most often they hit the ball from the ground (52 actions, with $2 \%$ effectiveness). They most effectively hit the ball dropped from a hand on the volley (7 actions, with 57\% effectiveness). The goalkeepers were inefficient in hitting the ball dropped from their hand in 'another way' (9 actions). It should be added that these actions constituted a small percentage of all offensive activities performed during the competition.

\section{Detailed models of the efficiency \\ of defensive actions}

\section{Preventing a loss of a goal}

It follows from the data presented in Table 7 that in preventing a loss of a goal, the examined goalkeepers most often applied pushing the ball (314 actions with $90 \%$ effectiveness) and defence without contact with the ball (266 actions, with 78\% effectiveness). When pushing the ball, they most often used robinsonade and push-out from place (131 and 59 actions, with 87\%

Table 7. Model of efficiency in preventing a loss of a goal

\begin{tabular}{|c|c|c|c|c|}
\hline \multirow{2}{*}{ Mode of action } & & & \multicolumn{2}{|c|}{ Forms of efficiency } \\
\hline & & & Activity & Successful activity \\
\hline \multirow{18}{*}{ Individual } & \multirow{6}{*}{ Catching the ball } & in place (without jumping) & 87 & 75 \\
\hline & & in half-kneeling & 36 & 32 \\
\hline & & in kneeling & 24 & 23 \\
\hline & & in jumping & 10 & 9 \\
\hline & & in robinsonade & 31 & 28 \\
\hline & & in a hurdle sit & 3 & 3 \\
\hline & \multicolumn{2}{|l|}{ Punching } & 2 & 2 \\
\hline & \multirow{6}{*}{ Pushing } & in place (without jumping) & 59 & 55 \\
\hline & & in half-kneeling & 39 & 37 \\
\hline & & in kneeling & 34 & 31 \\
\hline & & in jumping & 17 & 17 \\
\hline & & in robinsonade & 131 & 114 \\
\hline & & in a hurdle sit & 34 & 28 \\
\hline & \multicolumn{2}{|l|}{ Defence with feet } & 153 & 134 \\
\hline & \multicolumn{2}{|l|}{ Situational defence } & 43 & 34 \\
\hline & \multicolumn{2}{|c|}{ Defence in a $1 \times 1$ situation } & 71 & 58 \\
\hline & \multicolumn{2}{|c|}{ Saving shots after set-pieces } & 34 & 34 \\
\hline & \multicolumn{2}{|c|}{ Defence/intervention without contact with the ball } & 266 & 208 \\
\hline Cooperation & \multicolumn{2}{|c|}{ Consequential doubling } & 163 & 154 \\
\hline
\end{tabular}


A. Szwarc, M. Oszmaniec, A model of the efficiency of goalkeepers' actions in futsal

Table 8. Model of efficiency in preventing the creation of scoring situations

\begin{tabular}{llrr}
\hline \multirow{2}{*}{ Mode of action } & \multicolumn{2}{c}{ Forms of efficiency } \\
\cline { 3 - 4 } & & Activity & Successful activity \\
\hline \multirow{2}{*}{ Catching the ball } & 267 & 261 \\
& Punching & 8 & 8 \\
& Pushing & 19 & 15 \\
& Intercepting/clearing the ball with/without falling to the ground & 142 & 132 \\
& Defence/intervention without contact with the ball & 125 & 120 \\
\hline \multirow{2}{*}{ Cooperation } & Consequential doubling & 45 & \multirow{2}{*}{44} \\
\hline
\end{tabular}

and 93\% effectiveness, respectively). They were reliable when pushing the ball out in a jump (17 actions), and they pushed the ball the least efficiently in a hurdle sit (34 actions, with 82\% effectiveness). The examined top-level goalkeepers less often caught the ball or intervened with their legs (191 and 153 actions, respectively, with $89 \%$ and $88 \%$ effectiveness). The most often and the least effectively they caught the ball in place $(87$ actions, with $86 \%$ effectiveness). They did not fail in catching the ball in a hurdle sit (3 actions). They obtained equally high effectiveness in catching the ball in kneeling, jumping, and robinsonade (96\%, 90\%, and $90 \%$ effectiveness, respectively). The champions were $100 \%$ effective in punching ( 2 actions) and saving shots from set-pieces (34 actions). They also achieved high effectiveness during consequential doubling an action strictly dependent on partners' behaviour (163 actions, with 94\% effectiveness). In turn, they failed the most during defence without contact with the ball, situational defence, and $1 \times 1$ situations $(78 \%$, $79 \%$, and $81 \%$ effectiveness, respectively).

\section{Preventing the creation of scoring situations}

The data presented in Table 8 show that while preventing the creation of scoring situations, catching the ball (267 actions, with 98\% effectiveness) and intercepting/clearing the ball with/without falling to the ground outside the penalty area (142 actions, with 93\% effectiveness) dominated among the observed goalkeepers. The examined players did not fail in punching (8 actions). They obtained equally high effectiveness in consequential doubling in cooperation with partners and in intervention without contact with the ball (45 and 125 actions, with $98 \%$ and $96 \%$ effectiveness, respectively). In turn, they failed the most in pushing the ball (19 actions, with 79\% effectiveness).

\section{Discussion}

Comprehensive research on futsal goalkeepers' efficiency is scarce; therefore, the purpose of this study was to develop a model of efficiency for futsal goalkeepers with the consideration of their objectives in offensive and defensive play.

In the common understanding, the goalkeeper's role comes down to saving the goal effectively. Meanwhile, as shown in this study, the goalkeeper in modern futsal performs many more tasks, primarily in offensive game. Our research shows that offensive actions accounted for $58 \%$ and defensive actions for $42 \%$ of all actions applied by the examined futsal goalkeepers. FIFA experts have already noticed the advantage in using offensive actions over the defence game after the change in the 11-player soccer rules - the back-pass rule [35]. Later scientific research proved that the goalkeepers' involvement in offensive actions was 3-4 times greater than in the defensive game [36-38].

The examined players most often used actions aimed at gaining the playfield with the ball and measures to prevent a loss of a goal, which constituted, respectively, $41 \%$ and $28.2 \%$ of their whole activity. These results correspond with the reports by Kunze et al. [28], who, analysing the play of futsal goalkeepers in 13 matches of the Santa Catarina Championship in Brazil in 2012, showed that gaining the playfield mainly by passing the ball with the foot accounted for $40 \%$ of all actions taken by goalkeepers. It is worth adding that goalkeepers of 11-person teams present similar activity in these actions, as confirmed, among others, by Szwarc et al. [36].

Scoring goals was the least often performed and the most unreliable action applied by the examined futsal goalkeepers in the game (in total, they performed only 68 actions in all matches, with 7\% effectiveness). However, it should be noted that these actions were undertaken only in two game situations. The first one is 
a situation of an unfavourable result, usually in the last minutes of competition, while building a positional attack (building a 'castle' on the opposite team's defence field) by shooting the ball into the goal. Corrêa et al. [21] concluded, on the basis of the results of the game of 1170 players performing in an amateur futsal league (Carapicuíba, Brazil), that goalkeepers participating in offensive actions in the opponent's half contributed to increasing the efficiency of their team's play in attack, which was evident during shots at the goal (they shot at the goal 7 times more often than their opponents playing in the offensive position with the goalkeeper remaining in his half of the playfield). Vicente-Vila and Lago-Peñas [22] and Méndez-Domínguez et al. [23] also proved that as a result of the goalkeeper's participation in attack (positioning the game in attack by outnumbering), their efficiency in scoring goals increased several times. The second circumstance in which goalkeepers performed actions to score a goal was a game with a favourable result: upon intercepting (catching) the ball, the winning team's goalkeeper kicked it at the opponent's goal after dropping it from hand. As a rule, these were situations in which the losing team built a 'castle,' and with the goal abandoned by the goalkeeper, it created a numerical advantage in the opponent's half. Actions aimed at scoring by the goalkeeper are characteristic of futsal and in principle do not appear in the game of 11-person teams [36, 37].

The conducted research reveals that the examined players showed the highest effectiveness in keeping the ball (555 actions, with 97\% effectiveness) and in preventing the creation of scoring situations (606 actions, with $96 \%$ effectiveness). The players considered to be champions also successfully gained the playfield with the ball and prevented losing a goal (88\% and $87 \%$ effectiveness, respectively). The reliability indices presented in this paper are higher than those from reports by Rascón [24] and Paz-Franco et al. [29]. Rascón's analysis of goalkeepers playing in 5 matches of the Intercontinental Futsal Cup in 2008 and in 5 matches of the first Spanish league in the 2007-2008 season shows that the goalkeepers' effectiveness in preventing a loss of a goal equalled 74\%. Paz-Franco et al. proved that the effectiveness of goalkeepers from 8 leading teams of the first Spanish league during 16 matches of the Copa del Rey tournament was $76.5 \%$. The differences in effectiveness between the goalkeepers examined in this study and the players evaluated by the above-mentioned authors can be explained by the fact that the mentioned authors analysed the game of goalkeepers representing a significantly lower level of sports proficiency, while we involved goalkeepers of the highest level.
Our analysis shows that while preventing a loss of a goal, goalkeepers performed 1237 actions, and while preventing the creation of scoring situations, they took 606 actions, which constituted $28.2 \%$ and $13.8 \%$ of all types of actions used, respectively. Léo [39], analysing the game of futsal goalkeepers in 10 matches of the 2008 World Cup, reveals that preventing a loss of a goal and preventing the creation of a scoring situation constituted $36.4 \%$ and $12.5 \%$ of all actions taken by them, respectively. In turn, according to Vieira [25], who studied goalkeepers playing during the 2008 World Cup, and Leite [26], who investigated players of the Portuguese national futsal team, the percentage of actions against losing a goal amounted to $40 \%$ of all actions taken by goalkeepers in the game. Bearing in mind the different research approaches, one can assume that the results obtained in the cited studies are similar. The share of actions against losing a goal and creating scoring situations (counted together) in all of a futsal goalkeeper's actions is over $40 \%$.

Da Silva et al. [27], analysing 2 Brazilian goalkeepers during the Campeonato Gaúcho tournament in 2012, showed that in each of the 23 watched matches, they prevented losing a goal 15 times on average, with $80 \%$ effectiveness. In turn, Kunze et al. [28], considering the play of 3 professional goalkeepers in 13 matches during a tournament in Brazil in 2012, indicated that they prevented losing a goal 11 times in one match on average. However, our research implies that goalkeepers prevent losing a goal 20 times per match on average, with $87 \%$ effectiveness. The differences in the activity and effectiveness of these actions may be due to different sample sizes $(2,3$, and 23 players, respectively), a different number of observations of the subjects' game $(23,13$, and 62 , respectively), and different levels of the examined goalkeepers' sports proficiency. Unequivocal conclusions in this regard must be supported by further research.

While preventing a loss of a goal, the observed goalkeepers most often used actions relatively dependent on partners (individual actions) in pushing the ball (314 actions, with 90\% effectiveness) and defence without contact with the ball (266 actions, with 78\% effectiveness). When gaining the playing field with the ball, they most often applied actions strictly dependent on partners (cooperation) in throwing the ball with underhand swing and a short pass from the ground with a foot ( $42 \%$ and $19 \%$ of all actions, respectively). These observations corroborate the results obtained by Oszmaniec and Szwarc [30] when analysing goalkeepers' play in 8 matches of the World and European Futsal Championships in 2012. In offensive game, 
A. Szwarc, M. Oszmaniec, A model of the efficiency of goalkeepers' actions in futsal

the examined goalkeepers did not fail while passing the ball from a set-piece, while catching the ball after faking or dribbling it, or during a sliding tackle that kept the ball in play. Comparing their achievements with goalkeepers of 11-person soccer teams, it is worth noting [36-38] that futsal players undertook actions to create scoring situations almost 5 times more often.

In defensive actions, the examined players showed $100 \%$ effectiveness when catching the ball in a hurdle sit, punching, pushing the ball in a jump, and saving shots from set-pieces in preventing a loss of a goal and when punching in preventing the creation of scoring situations. The conducted research reveals that futsal goalkeepers most often intervened in the penalty area, which is also confirmed by other researchers $[24,29,40]$ and analysts dealing with goalkeepers of 11-person soccer [41, 42].

\section{Conclusions}

To sum up, in attack, futsal goalkeepers usually use actions aimed at gaining the playfield with the ball, and in defence - against losing a goal. In attack, they apply actions strictly dependent on partners (cooperation) more often, while in defence, the actions are relatively dependent on partners (individual actions). However, they obtain higher effectiveness in individual offensive actions than in joint defensive actions.

The created model mapping the top-skilled goalkeepers' actions allows to improve the process of coaching players by referring their game to objective patterns.

\section{Disclosure statement}

No author has any financial interest or received any financial benefit from this research.

\section{Conflict of interest}

The authors state no conflict of interest.

\section{References}

1. Vestberg T, Gustafson R, Maurex L, Ingvar M, Petrovic P. Executive functions predict the success of topsoccer players. PLoS One. 2012;7(4):e34731; doi: 10.1371/journal.pone.0034731.

2. Lepschy H, Wäsche H, Woll A. How to be successful in football: a systematic review. Open Sports Sci J. 2018;11:3-23; doi: 10.2174/1875399X01811010003.

3. Mackenzie R, Cushion C. Performance analysis in football: a critical review and implications for future research. J Sports Sci. 2013;31(6):639-676; doi: 10.1080/026 40414.2012.746720.

4. Impellizzeri FM, Marcora SM, Coutts AJ. Internal and external training load: 15 years on. Int J Sports Physiol
Perform. 2019;14(2):270-273; doi: 10.1123/ijspp.2018 -0935 .

5. O’Donoghue P. Research methods for sports performance analysis. Abingdon: Routledge; 2010.

6. Memmert D, Rein R. Match analysis, Big Data and tactics: current trends in elite soccer. Dtsch Z Sportmed. 2018;69(3):65-72; doi: 10.5960/dzsm.2018.322.

7. Hughes MD, Bartlett RM. The use of performance indicators in performance analysis. J Sports Sci. 2002; 20(10):739-754; doi: 10.1080/026404102320675602.

8. Panfil R. A paradigm for identifying ability competition (providing examples of sport game and fight). Hum Mov. 2011;12(1):16-23; doi: 10.2478/v10038-011-0002-1.

9. Sarmento H, Marcelino R, Anguera MT, Campaniço J, Matos N, Leitão JC. Match analysis in football: a systematic review. J Sports Sci. 2014;32(20):1831-1843; doi: 10.1080/02640414.2014.898852.

10. Gómez MA, Moral J, Lago-Peñas C. Multivariate analysis of ball possessions effectiveness in elite futsal. J Sports Sci. 2015;33(20):2173-2181, doi: 10.1080/02640414. 2015.1075168.

11. Agras H, Ferragut C, Abraldes JA. Match analysis in futsal: a systematic review. Int J Perform Anal Sport. 2016;16(2):652-686; doi:10.1080/24748668.2016.118 68915.

12. Corrêa UC, de Pinho ST, da Silva SL, Clavijo FAR, de Oliveira Souza T, Tani G. Revealing the decision-making of dribbling in the sport of futsal. J Sports Sci. 2016; 34(24):2321-2328; doi: 10.1080/02640414.2016.123 2488.

13. Goliński D, Muracki J, Wolański P, Klich S, MurawskaCiałowicz E. Small-sided soccer game (1v1) in goalkeepers' training. CentEur J Sport Sci Med. 2016;16(4):111118; doi: 10.18276/cej.2016.4-12.

14. Sarmento H, Bradley P, Anguera MT, Polido T, Resende R, Campaniço J. Quantifying the offensive sequences that result in goals in elite futsal matches. J Sports Sci. 2016;34(7):621-629; doi: 10.1080/02640414. 2015.1066024.

15. Göral K. Analysis of Serbia UEFA Futsal Euro 2016 competitions in terms of some variables. J Educ Train Stud. 2018;6(10):1-6; doi: 10.11114/jets.v6i10.3343.

16. Méndez C, Gonçalves B, Santos J, Ribeiro JN, Travassos B. Attacking profiles of the best ranked teams from elite futsal leagues. Front Psychol. 2019;10:1370; doi: 10.3389/fpsyg.2019.01370.

17. Gómez MA, Méndez C, Indaburu A, Travassos B. Goal effectiveness after players' dismissals in professional futsal teams. J Sports Sci. 2019;37(8):857-863; doi: 10.1080/02640414.2018.1531498.

18. Pazetto NF, Gaino JGM, dos Santos CD, de Oliveira Spinosa RM, de Santo DL, Marques I. Comparison of the pass skill between professional and U-15 futsal players under different organization contexts. Hum Mov. 2020;21(2):58-63; doi: 10.5114/hm.2020.89915.

19. Aires AHB. The variations in the use of tactics of futsal goalkeeper lines do not change the results of the São 
Paulo Cup games [in Portuguese]. Rev Bras Futsal Futebol. 2011;3(8):101-107.

20. Ribeiro N. The influence of goalkeeper line on the results in a futsal game [in Portuguese]. Rev Bras Futsal Futebol. 2011;3(9):187-198.

21. Corrêa UC, Davids K, Silva SL, Denardi RA, Tani G. The influence of a goalkeeper as an outfield player on defensive subsystems in futsal. Adv Phys Educ. 2014; 4(2):84-92; doi: 10.4236/ape.2014.42012.

22. Vicente-Vila P, Lago-Peñas C. The goalkeeper influence on ball possession effectiveness in futsal. J Hum Kinet. 2016;51:217-224; doi: 10.1515/hukin-2015-0185.

23. Méndez-Domínguez C, Gómez-Ruano MA, Rúiz-Pérez LM, Travassos B. Goals scored and received in 5vs4 GK game strategy are constrained by critical moment and situational variables in elite futsal. J Sports Sci. 2019;37(21):2443-2451; doi: 10.1080/02640414.2019. 1640567.

24. Rascón JM. Where does the goal mistake lie in futsal? [in Spanish]. Rev Int Deportes Colec. 2009;2:36-57.

25. Vieira CP. Futsal: scout proposal and analysis of offensive termination actions in men's Futsal World Cup 2008 games [in Portuguese]. Campinas: Universidade Estadual de Campinas; 2010.

26. Leite WSS. Analysis of the offensive process of the Portuguese futsal team. Pamukkale J Sport Sci. 2012;3(3): 78-89.

27. Da Silva EMN, Borfe L, Burgos LT. Analysis of the technical level of the goalkeepers of ASSAF - Santa-Cruzense Futsal Association - in the gold series championship of the state of Rio Grande do Sul in 2012 [in Portuguese]. Cinergis. 2012;13(4):20-25; doi: 10.17058/ cinergis.v13i4.3789.

28. Kunze A, Schlosser MW, Brancher EA. Analysis of the most used goalkeeping techniques during men's futsal games [in Portuguese]. Rev Bras Futsal Futebol. 2016; 8(30):228-234.

29. Paz-Franco A, Bores-Cerezal A, Barcala-Furelos R, Mecias-Calvo M. Analysis of the conducts of elite futsal goalkeeper in the different situations of the game. Am J Sports Sci Med. 2014;2(3):71-76; doi: 10.12691/ajssm2-3-1.

30. Oszmaniec M, Szwarc A. The efficiency of actions of goalkeepers from sports effective teams in a game of futsal in matches of the final tournament of the World and European Championships in 2012. Balt J Health Phys Act. 2015;7(4):15-27; doi: 10.13140/RG.2.1.2265. 1281.

31. Panfil R. Praxeology of sports games [in Polish]. Wrocław: AWF; 2006.

32. Duda H, Brzyski J. Identification of the efficiency of football players in individual high-risk situations (on the example of the Polish national team's performance in the EURO 2012 tournament). J Kinesiology Exercise Science. 2016;74(26):63-71; doi: 10.5604/01.3001. 0009.5614 .
33. Szwarc A, Oszmaniec M, Lipinska P. The method of goalkeeper's evaluation in futsal. Balt J Health Phys Act. 2014;6(2):100-113; doi: 10.2478/bjha-2014-0010.

34. Duda H, Mucha D, Ambroży T, Omorczyk J, Makuch R, Mucha D. Praxeological evaluation of the efficiency in offensive activities of the individual football players as a determinant in rationalizing and shaping a sports game. Balt J Health Phys Act. 2018;10(4):49-60; doi: 10.29359/BJHPA.10.4.04.

35. FIFA. Technical study group reports. Available from: https://www.fifa.com/who-we-are/official-documents/development/technical-study-group-reports.

36. Szwarc A, Lipińska P, Chamera M. The efficiency model of goalkeeper's actions in soccer. Balt J Health Phys Act. 2010;2(2):132-138; doi: 10.2478/v10131-0013-x.

37. Liu H, Gómez MA, Lago-Peñas C. Match performance profiles of goalkeepers of elite football teams. Int J Sports Sci Coach. 2015;10(4):669-682; doi: 1260/17479541.10.4.669.

38. Sainz de Baranda P, Adán L, García-Angulo A, GómezLópez M, Nikolic B, Ortega-Toro E. Differences in the offensive and defensive actions of the goalkeepers at women's FIFA World Cup 2011. Front Psychol. 2019; 10:223; doi: 10.3389/fpsyg.2019.00223.

39. Léo LAC. Descriptive study of the technical and tactical level of futsal goalkeepers in futsal World Cup 2008 [in Portuguese]. Belo Horizonte: Universidade Federal de Minas Gerais; 2010.

40. Abdel-Hakim HH. Quantitative analysis of performance indicators of goals scored in the Futsal World Cup Thailand 2012. Pamukkale J Sport Sci. 2014;5(1): 113-127.

41. Sainz de Baranda P, Ortega E, Palao JM. Analysis of goalkeepers' defence in the World Cup in Korea and Japan in 2002. Eur J Sport Sci. 2008;8(3):127-134; doi: 10.1080/17461390801919045.

42. Szwarc A, Jaszczur-Nowicki J, Aschenbrenner P, Zasada M, Padulo J, Lipinska P. Motion analysis of elite Polish soccer goalkeepers throughout a season. Biol Sport. 2019;36(4):357-363; doi: 10.5114/biolsport.2019. 88758. 